This item was submitted to Loughborough's Research Repository by the author.

Items in Figshare are protected by copyright, with all rights reserved, unless otherwise indicated.

\title{
Sport, outdoor life and the Nordic world: an introduction
}

PLEASE CITE THE PUBLISHED VERSION

https://doi.org/10.1080/17430437.2017.1390927

PUBLISHER

(c) Taylor and Francis

VERSION

AM (Accepted Manuscript)

PUBLISHER STATEMENT

This is an Accepted Manuscript of an article published by Taylor \& Francis in Sport in Society on 05 Feb 2018, available online: https://doi.org/10.1080/17430437.2017.1390927

\section{LICENCE}

CC BY-NC-ND 4.0

\section{REPOSITORY RECORD}

Bergsgard, Nils Asle, Solfrid Bratland-Sanda, Richard Giulianotti, and J.O. Tangen. 2019. "Sport, Outdoor Life and the Nordic World: An Introduction". figshare. https://hdl.handle.net/2134/32164. 
Sport, Outdoor Life and the Nordic World:

An Introduction

Nils Asle Bergsgard, Solfrid Bratland-Sanda, Richard Giulianotti, Jan Ove Tangen 
This special issue of Sport in Society examines the interrelationships of sport, outdoor life, and society across the 'Nordic region', which is made up of the sovereign nations of Denmark, Finland, Iceland, Norway and Sweden. Our aims in putting together this special issue are two-fold. First, we seek to advance knowledge of Nordic sport and outdoor life, as important fields of social activity in their own rights. Second, we aim to enhance understanding of the 'Nordic model' of society, and the ways in which this is constructed, explored and challenged within and through sport and outdoor life activities.

In doing so, our twelve papers explore a range of key themes, notably: how modern Nordic sport and outdoor life activities emerged and are organized through specific social policies; how they may challenge or harbor forms of social exclusion, particularly in regard to gender or minority populations; how they are affected by, and respond to, deviant practices such as doping; how they may contribute to alleviating social problems; and, how they confront major structural challenges and changes, such as the impacts of globalization and the continuing dominance of neoliberal economic policies. Our approach is concertedly interdisciplinary, and draws fully on the disciplines of anthropology, history, pedagogy, political science, psychology, social policy, and sociology, as well as the diverse 'studies' fields of area, cultural, ethnic, gender, and global studies.

The special issue is timely for both Nordic and international audiences in two main senses. First, there is significant interest across other regions in Nordic sport and outdoor life. This interest relates to the relative successes of elite-level Nordic athletes and teams (for example, the Icelandic national football team or Norwegian skiers); the strong grassroots sport and physical activity cultures within Nordic societies; and, the distinctive cultures of outdoor life across much of the Nordic region. Second, there is a wider international interest in the Nordic 'way of life', ranging from the highly successful values of democracy, egalitarianism, and work-life balance, through to popular cultural aspects such as in household design, 'Nordic 
noir' novels and television series, or broad cultural mentalities (such as Danish hygge, or feeling of cosiness).

In turn, we seek also to contribute substantially to academic understandings of Nordic sport, outdoor life and societies, by moving to fill significant gaps in these research areas. Two prior collections of papers have focused on these areas, but in rather different ways. First, a special issue of Sport in Society (2010) examined sport in Scandinavia; as such, this valuable collection, published almost a decade before our own, was narrower in its regional range, and did not consider the full Nordic domain including Finland or Iceland. Second, an earlier special issue of the same journal examined more widely the Nordic world and sport, but with a largely historical focus on areas such as pre-industrial Swedish sport or interwar sport cultures (Meinander \& Mangan 1997). Our special issue has the scope to go much further than both of these collections in several ways: first, in addressing Nordic rather than only Scandinavian societies; second, in considering Nordic sport through a broader mix of disciplinary lenses; third, in exploring the wider realm of outdoor life as well as modern sport; fourth, in exploring what is distinctive about Nordic sport and society vis-a-vis other global regions (cf. Bairner 2010); and fifth, in our critical engagement with the mythologies surrounding the 'goodness' of Nordic sport, outdoor life and society.

To set the scene for this special issue, our introduction is organized into four main parts. First, we explain what we mean by the basic terms of sport, outdoor life, and the Nordic region. We then turn to discuss and to outline the key features of the 'Nordic model' of society and sport. Third, we consider how the Nordic model may be critiqued, and the ways in which it continues to be a relevant concept. Finally, we outline the article contents of this special issue. 


\section{Sport and Outdoor Life in the Nordic Region}

In what follows, our approach is to work with a relatively conventional definition of sports. We thus understand sports as encompassing the usual range of modern, standardized, competitive physical disciplines such as football (soccer), handball, and track-and-field athletics. To those disciplines, we add our further interest in a wider array of physical cultural activities, particularly at everyday level and which are often sport-related, and these include jogging, swimming, and walking.

We are also concerned with the special Nordic variety of outdoor life activities - or friluftsliv, to borrow the Norwegian term - such as trekking, sailing, mountaineering, and skiing. These activities play an important role in the Nordic 'way of life', in underpinning cultural relationships with nature and the outdoor world, and in shaping of local, national and regional identities. As an academic subject area, friluftsliv and other types of 'outdoor life studies' are commonly researched and taught alongside sport disciplines in colleges and universities across the Nordic region.

Our focus on the Nordic region relates to the sovereign nations of Denmark, Finland, Iceland, Norway, and Sweden, which have deep geographical, historical, social, and cultural ties. Denmark, Norway and Sweden make up the Scandinavian nations, Finland shares borders with Sweden and Norway, while the island of Iceland is located in the circumpolar North, between Norway and Greenland, itself a constituency of Denmark. The entire Nordic population is relatively small, totaling around 27 million people, with the largest proportion being located in Sweden (almost 10 million), followed by Denmark, Finland and Norway (around 5-6 million each), and Iceland (around 350,000). Nordic nations have relatively strong regional identities, which tend to reference common ancestry going back to the Viking era from the late $8^{\text {th }}$ to $11^{\text {th }}$ centuries, the subsequent influence of the Lutheran church and its associated values, and, in all cases except Finland, have a set of national languages that have a 
common heritage. Modern Nordic societies have also been characterized by relatively advanced and strong economies, extensive ties in trade and politics, high levels of national income and wealth, and their following of a distinctive 'Nordic model' in politics, economy, and society, centring on social democracy and relatively strong welfare states.

\section{The Nordic Model: Making Utopia?}

For its proponents, the Nordic model has a variety of strengths and benefits for its citizens and the wider world. First, the Nordic model is viewed as being underpinned by a distinctive family of values that emphasize equality, tolerance, consensus, cooperation and fairness. ${ }^{1}$ These values give rise to relatively high levels of gender equality, and to the effective social integration of ethnic minorities and refugees. These powerful national values may be traced in part back to pre-modern societies and cultures, for example to the Lutheran influence and to strong degrees of regional autonomy from the centre, which allowed for the inculcation of powerful work ethics, high levels of literacy, egalitarianism and social democracy.

Second, the Nordic model is deeply associated with modern social democracy. The main characteristics of this model include: a strong welfare state and provision of public services that are financed by relatively high taxes; high spending on 'human capital', such as childcare, education, and research and development; high levels of social capital and trust across the members of the society; and, a strong civil society that is supported by the state (see for example Esping-Andersen 1990; for sport especially see Bergsgard and Norberg 2010, and Bergsgard et.al. 2007: 6ff). ${ }^{2}$ Modern Nordic economic and industrial policies have tended to be founded upon a tripartite political model, which brings together the state,

\footnotetext{
${ }^{1}$ Reflecting the power of Nordic civic values, one study found that the Norwegian middle-classes prioritized two normative ideal-types: "the good Samaritan" and "the socially responsible citizen" (Sakslind and Skarpenes 2014).

${ }^{2}$ See http://www.norden.org/no/aktuelt/artikler/201con-top-of-the-world201d.
} 
employers and trade unions. At the same time, Nordic state and civil society relations are viewed as interdependent and mutually beneficial, rather than based upon a competitive zerosum game (Trägårdh 2010).

Third, Nordic societies have relatively strong historical and cultural ties to the countryside and rural ways of life. Outdoor life and the environment are significant themes in Nordic societies, which are evidenced partly by the long-standing tradition across Nordic populations of making visits to rural and often highly remote cabins.

Fourth, Nordic societies display relatively high levels of internationalism, as reflected in strong commitments to supporting international aid and development work, with sustained backing for international organizations such as the United Nations and development NGOs. Other aspects of the Nordic model here include records of leading peace talks and peacebuilding in conflict zones; and, wider commitments to environmentalism, sustainability, and tackling climate change. More generally, Nordic societies tend to act as global 'norm entrepreneurs’ for open democracy, transparency, human rights, social justice, and full human development (Ingebritsen 2002; Lawler 1997).

Fifth, global surveys point to the success of the Nordic model. Nordic countries routinely come at or near the top of surveys that measure life evaluation, GDP, education, social mobility, life expectancy, public health, employment levels, equality, work-life balance, and population happiness (Deaton 2013; Wilkinson and Pickett 2009). To pick but one example, the World Economic Forum produces an annual Inclusive Development Index (IDI), which compares international levels of social inclusion against a range of national key performance indicators such as poverty, inequality, employment, and environmental conditions. Nordic nations dominate the highest scores: in 2017, Norway was ranked as the most inclusive nation, with Iceland, Denmark and Sweden also featuring in the world's top six (WEF 2017). 
Overall, these factors lead some proponents to present the Nordic region as a kind of modern utopia, with progressive social systems that underpin and promote social democracy, equality, tolerance, inclusion and fairness. This regional way of life appears to stand in sharp contrast to other advanced modern societies in Western Europe and North America, which have taken more market-orientated approaches, and have been more associated with social inequalities and divisions, international conflicts, and lower qualities of life.

In sport, physical culture, and outdoor life, we may point initially to three ways in which the Nordic model is manifested. First, a strong discourse in Nordic politics and societies is that, compared to much of Europe and North America, state policies on sport have tended to prioritize mass sport participation at grassroots level ('sport for all') rather than to provide financial backing for elite-level sport competitors and competitions. ${ }^{3}$

Second, we might expect the Nordic model to permeate the organizational culture of sport, friluftsliv and physical culture across the region. Thus, in ideal terms, sport and friluftsliv organizations should reflect the Nordic commitment to democracy and egalitarianism in how they are run; these clubs should also display high levels of gender equality in participation and decision-making, and a focus on building community (and social capital) by assisting the positive socialization and integration of different social groups.

Third, the internationalism of the Nordic model has been extolled in sport in a variety of ways. For example, there has been a prominent Nordic commitment to stated Olympic values relating to peace, internationalism and the environment, as reflected at the 1994 Winter Olympics in Lillehammer, Norway. Moreover, Scandinavian nations have been active since at least the 1980s in assisting low- and middle-income nations to develop their sport

\footnotetext{
${ }^{3}$ We say 'discourse' here, as the evidence indicates that, for local sports clubs, their share of income from government support is no higher in Norway than in Germany, England or Canada (Bergsgard et. al. 2007; Augestad, Bergsgard \& Hansen 2006). It is also hard to find good comparable international data on government support for elite-level sport (Bergsgard 2011; Andersen and Rongland 2012).
} 
infrastructures while also using sport to promote norms that are centred on peace, gender equality, human rights and democracy.

\section{Potential Criticisms or Limitations of the Nordic Model}

The Nordic model of sport and society may appear as an exceptional social democratic utopia, but are there ways in which this ideal may be qualified or even criticized? Several points may be made here.

First, in historical terms, the Nordic social democratic consensus has been contested, and has not always been in place in modern times. For example, Moene and Wallerstein (2006) report that, in much of the interwar period, Norway and Sweden encountered 'the highest levels of industrial conflict in the world', with hundreds of working days lost due to lockouts and strikes. One study examining the long-term record of Nordic economies over the past three thousand years found that the region did not have a noticeable long-term record in the social distribution of wealth. However, living standards and intergenerational mobility did show exceptionally low levels of inequality compared to most other advanced economies (Fochesato and Bowles 2015).

Second, in comparative terms, there are significant national variations across the region in how the 'Nordic model' is put into practice. These variations reflect the fact that the Nordic region, while appearing as a whole at the conceptual level, is not made or experienced in exactly the same way at the everyday level, but instead is marked by other cross-cutting cultural influences at local, national and transnational levels. ${ }^{4}$ In addition, the Nordic region is not the only part of the world to play up its own sense of uniqueness. The United States,

\footnotetext{
${ }^{4}$ Additionally, differences arise across Nordic countries over health interventions: for example, in treating health disorders, Finland puts relatively less emphasis than Norway on mental health and substance abuse, and a greater preponderance of work into somatic illnesses such as type 2 diabetes.
} 
for example, has been associated with following an ‘exceptional path’ (sonderweg) of modern development since at least the 1830s (De Tocqueville 1840).

Third, both theoretical and empirical arguments may be made that the Nordic model is highly idealized and that these societies remain weak or regressive in key areas of social democracy. For example, Nordic penal policies are double-edged, in promoting individual wellbeing, humaneness and social solidarity, but also restricting liberties, social inclusion and human rights (Barker 2013). Additionally, Nordic societies still harbour deep-seated social inequalities and divisions along the lines of class, race, and gender. Even in the regulated institutions of sport, we find that these weaknesses are borne out in statistical terms. For instance, in regard to gender equality, Ottesen et al. (2010: 659) observed that, in sport associations, “despite the high percentage of female members, women are under-represented on executive boards”. In addition, the indigenous Sámi populations experienced extended modern histories of forced assimilation into specific national models of politics, culture, economy and society across the Nordic region.

A related, critical argument may be that there is a shadow side to the strong Nordic state: for example, behind the internationalism of development work in Africa, we find that once again forms of Nordic (and 'global North') patronage and even control are being exercised over poor and marginalized populations in the global South. A further critical argument here might be that the Nordic countries are 'regimes of goodness'. This concept is used by Tvedt (2003) in his analysis of Norwegian foreign aid policy towards the global South. For Tvedt, this 'regime of goodness' puts greater emphasis on the ideal of being morally good - in possessing and being seen to exercise the right values - rather than on securing actual positive impacts and consequences for these international policies (Tvedt 2003).

Fourth, proponents of the Nordic model appear to assume that strong forms of social homogeneity and integration are in place in each nation. However, we might argue that such 
uniformity, if it ever existed, is more difficult to identify in late modern times, due to the influences of migration and social, cultural and economic globalization.

Finally, political economic arguments may contend that the Nordic model has been challenged or even outmoded by new political movements, ideologies and economic policies. Different parts of the Nordic region have experienced the spread and popularization of free market economics, the election of centre-right or right-wing governments, the rise of Far Right movements, and the occurrence of populist protests against refugees and ethnic minorities. Some right-wing analysts have contended that the Nordic model of social democracy is economically unsustainable and that its ‘utopian’ status was greatly exaggerated in the first place (Sanandaji 2015, 2016). ${ }^{5}$

As potential markers of political and social change, these processes and discourses come into conflict with the Nordic model. Yet, the ethos of social democracy retains a powerful hold as an organizing principle and policy anchor across the region. The welfare state continues to have a strong economic and social role. Indeed, many of the Nordic region’s right-wing parties embrace the welfare state, and argue for example that their policies on restricting immigration are aimed at protecting welfare services. Elsewhere, we find that the countryside and outdoor life remain intrinsic to Nordic culture and society, while strong involvement in international development continues to emphasize social democracy and justice. And, without ignoring the financial crisis that engulfed Iceland, the Nordic region as a whole displayed remarkable resilience in facing the global economic downturn from 2007 onwards, as assisted by a relatively strong state sector (Gylfason 2010: 255). Thus, overall, the Nordic

\footnotetext{
${ }^{5}$ For example, a report published by the Institute of Economic Affairs and entitled Scandinavian Unexceptionalism: Culture, Markets and the Failure of Third-Way Socialism, critiqued the 'Scandinavian model' by claiming that the region's economic growth, wealth generation, reductions in inequality, and strong health data, were largely established before social democratic policies came into effect (Sanandaji 2015; see also 2016). One example that is provided to show the apparent failure of the Scandinavian model relates to how some Swedish men go absent from work when sporting events taking place.
} 
model will remain a critical reference point for the cultural, economic, social and political development of sport and physical culture across the region.

\section{Special Issue Contents}

Our special issue is comprised of twelve papers which explore the intersections of Nordic sport, outdoor life, and the social democratic models across the region. We open with two papers that examine two major fields in which the Nordic model of sport and society is manifested: in public policy and sport; and, in the interface of civil society, state and sport.

The first paper examines the policy and politics that lie behind the building of sport facilities in Nordic countries. The authorial team of Nils Asle Bergsgard, Katja Borodulin, Josef Fahlen, Jens Høyer-Kruse and Evald Bundgård Iversen addresses this issue with a particular comparative focus across four Nordic nations, Denmark, Finland, Norway and Sweden. The authors underline the similarities across these nations with regard to size, culture, politics, development, and the relative strength of their social democratic welfare systems. They argue that the structure for sport facilities in the Nordic countries implies public-non-public partnerships, negotiations, and, thus, governance. However, due to the high involvement of the public side when it comes to planning, funding and owning sport facilities, it is still fair to say that compared to general sport policy, facility policy is slightly more characterised by government than by governance. The public authorities’ involvement in funding sports facilities is greater than its general involvement in supporting sporting activity. When it comes to the national structure for sport facilities, there are significant national differences, both related to whichever level - national, regional or local - is most prominent, and whether it is the government or the sport clubs that set the agenda for sport facility policy. One rather 
surprising characteristic of the facility policy for sport in all of the Nordic countries, is that the non-public side, be it sport clubs, private companies or trusts, plays such a major role.

We then turn to explore the role of civil societies within Nordic sport. The Nordic region is widely understood to have thriving civil societies of community associations and other organizations that are given substantial state support. The paper by Richard Giulianotti, Hannu Itkonen, Arto Nevala, and Anna-Katriina Salmikangas examines how sport is created and shaped within the Nordic civil sphere. Opening with a discussion of the key tenets of the Nordic model, the authors then provide an illustrative study of Finnish sport, revealing the state's critical role in developing sport within civil society associations through much of the $20^{\text {th }}$ century. Over the last few decades, globalization processes may have had double-edged impacts for the Nordic model in both enabling its promotion across other regions and continents, and spreading opposing neoliberal social and economic policies. The authors explore also the major contribution of Nordic countries to global civil society in sport, through the use of sport to pursue wider development goals such as peace-building, gender equality, health education and crime reduction, primarily in low- and middle-income countries.

Our next pair of papers provides critical explorations of Nordic outdoor life (or friluftsliv) by exploring in particular the impacts of modernization processes upon this 'traditional' way of life. To understand the modern social history of friluftsliv, the paper by Cleng Eikje, André Horgen and Johan Arnegård focuses on the organization and professionalization of mountainguiding from the 1820s through to the current day. The authors provide a strongly comparative analysis of different nations within the Nordic region and with other parts of Europe. Prominent national differences include the regulation of mountain-guiding, with Norway featuring low regulative levels compared to much higher levels in France, Switzerland and Sweden. These divergences also reflect contrasting national approaches to 
the 'professionalization' of guides, and thus to the influence of modernizing impulses upon Nordic outdoor cultures.

Urban and sports development are two further ways in which modernization processes may squeeze or challenge friluftsliv spaces and cultures. The paper by Kirsti Pedersen Gurholt and Trygve B. Broch examines these questions through a case study of a Norwegian controversy in which proposed new laws were intended to advance the potentially competing interests of nature, outdoor life and sport. The authors note how, as the public debate ensued on this issue, major division arose between those supporting a protectionist stance towards nature and their opponents who favoured sport development policies. The episode revealed the critical tension in Norway, as elsewhere, which centres on how natural and social worlds may interact harmoniously, in the context of competing policy interests over outdoor life, health and sport.

Our next three papers explore different aspects of the interface between sport and social divisions. The paper by Eivind Skille draws our attention to majority and ethnic minority relations by examining the position of the indigenous Sámi populations across the northern Nordic region. Skille argues that Sámi sports populations and organizations are not fully engaged by the Nordic welfare or social democratic model. Drawing on the sociological approach of Bourdieu as well as wider postcolonial theorizing, he takes a critical view of majority-minority relations in sport and the wider society, noting that recent attempts by Nordic states to revitalize the Sámi have still tended to be based on the assumption and organizational logic that the majority populations need not be involved or engaged in this process. At the same time, Sámi populations often take a 'bicultural' approach towards their national identities - for example, as Sámi and as Norwegian - notably in how they celebrate athletes who formally represent the modern nation-state on the world stage.

The paper by Åse Strandbu, Anders Bakken, and Mira Sletten also explores sport-related issues for majority and ethnic minority populations. The specific focus here is on sport 
participation among majority and ethnic minority young people in Oslo, Norway, with reference to the cross-cutting influence of gender. The authors found that, for boys, there was relatively little difference between majority and minority communities. However, for girls, the picture is rather more complicated, with minority young people participating less in sport than those from the majority communities. To explain these differences, the authors note the influence of socio-economic and religious factors. Yet, other factors, including discrimination, were also understood to have some impact in shaping these divisions.

The position of women in sport is also addressed critically in the next paper with specific reference to how gendered identities are constructed within the mass media. The authors, Gerd von der Lippe and Jorid Hovden, indicate that, while media sport in general has tended to be heavily gendered, it is striking that Norway, which has relatively higher levels of gender equality, has also reflected this division. The authors probe this issue further through a study of online media coverage of sport which draws largely on a discourse analysis approach. They find that this media content continues to represent women in sport in heavily gendered and 'othering' ways. Yet, some different narratives and portrayals point to alternative ways in which women in sport may be portrayed in more progressive ways.

We move next to two papers that consider how the Nordic model engages with social problems arising within and without the sporting realm. The paper by Jan Ove Tangen and Verner Møller examines how Nordic societies respond to doping episodes within sport. Focusing on Norway, Denmark and Sweden, the authors consider three specific doping incidents involving national elite athletes and the resulting media coverage. The authors highlight how a substantial tension may arise, between national self-images and narratives, which include references to strong moral standards, and the logic of sport, which points to the need for rule-breakers to be dealt with consistently and objectively. The authors conclude that 
Nordic anti-doping is pursued with rigour and determination, almost as a form of Nordic exceptionalism rooted in ideologies of social welfare and strong paternalism.

We then consider how Nordic societies adopt an innovative and progressive approach towards the use of sport and physical activity, to help people who are facing major personal and social crises. The paper by Solfrid Bratland-Sanda, Eva Andersson, James Best, Simon Høegmark and Kirsten Kaya Roessler addresses this issue by examining the role of physical activity and outdoor life in tackling mental health problems in the Nordic region. The authors underline the seriousness of this health problem, and how these interventions have much stronger potential than the use of medications for securing long-term benefits. Examples are provided of these treatments from Norway, Sweden and Denmark, including how innovative collaborations between health services, nature guides, and sport and outdoor organizations may put together beneficial treatments that engage with the environment, exercise, and culture.

We conclude with three papers which explore how Nordic values and identities interact with key components of elite-level modern sport. The paper by Liv Hemmestad and Robyn Jones examines how one Norwegian coach in elite-level women's handball sought to move away from a modern, rationalized, scientific, and hierarchical performance system, in order to reinstall more Nordic values of egalitarianism and integration amongst the players. The authors consider in particular how opposition arose at times within the club to this fresh, Nordic approach, and how the coach sought to respond in order to secure change.

We then turn to examine how Nordic approaches have contributed significantly to the successes of international sport teams from the region. The paper by Frode Telseth and Vidar Halldorsson focuses on the remarkable successes of two Nordic sporting models, namely Norway in the 1990s and Iceland in the 2010s in men’s international football. Comprised of small nations, the Nordic region in theory should struggle to assert itself competitively within 
elite global sport, yet these two national teams celebrated epic victories against much stronger opponents from larger nations. The authors explore the extent to which these successes may be attributed at least in part to a 'Nordic mentality'; how these nations benefitted from striking an appropriate balance between the Nordic concerns with democracy (producing citizens) and competition (producing winning athletes); and how, when there is a shift away from a strong collectivist ethos, the competitiveness of these national teams has been jeopardized.

The final paper, by Torbjörn Andersson and Hans Hognestad, addresses the pressing contemporary issue of globalization within Nordic sport through an historical and sociological discussion of transnational influences on Scandinavian football. The authors note that these global forces helped to establish and to develop football in Scandinavia through late $19^{\text {th }}$ and much of the $20^{\text {th }}$ centuries, as the game was introduced to the region by the British, and as many local players and spectators subsequently looked abroad for knowledge and inspiration. Latterly, the intensified globalization of football has had profound impacts across Scandinavia, particularly in transnational player migration and fan identifications. The authors explore in particular how Scandinavian football is 'glocalized', as the game harbours both deep local roots and loyalties alongside powerful transnational affinities. 


\section{References}

Andersen, S.S. and L.T. Rongland (eds) (2012) Nordic Elite Sport: Same Ambitions Different Tracks, Oslo: Universitetsforlaget.

Augestad, P., N.A. Bergsgard and A.Ø. Hansen (2006) 'The Institutionalization of an Elite Sport Organization in Norway: The Case of “Olympiatoppen”, Sociology of Sport Journal, 23(3): 293-313.

Barker, V. (2013) 'Nordic Exceptionalism Revisited: Explaining the Paradox of a JanusFaced Penal Regime', Theoretical Criminology, 17(1): 5-25

Bergsgard, N. A., P. Mangset, B. Houlihan, S.I. Nødland \& H. Rommetvedt (2007) Sport Policy: A Comparative Analysis of Stability and Change, Amsterdam: ButterworthHeinemann.

Bergsgard, N.A. (2011) 'Eliteidrettens virvelstrømmer. Norge (og naboerne) I verden’, Idrottsforum, available at: www.idrottsforum.org/articles/bergsgard/bergsgard110420.html

Bergsgard, N.A. and J. Norberg (2010) 'Sport Policy and Politics - the Scandinavian Way', Sport in Society, 13(14): 567-582.

Deaton, A. (2013) The Great Escape: Health, Wealth and the Origins of Inequality, Princeton: Princeton University Press.

Fochesato, M. and S. Bowles (2015) 'Nordic Exceptionalism? Social Democratic Egalitarianism in World-Historic Perspective', Journal of Public Economics, 127: 30-44.

Gylfason, T., B. Holmström, S. Korkman, H.T. Söderström and V. Vihriälä (2010) Nordics in Global Crisis: Vulnerability and Resilience, Helsinki: Taloustieto Oy.

Ingebritsen, C. (2002) ‘Norm Entrepreneurs: Scandinavia’s Role in World Politics’, Cooperation and Conflict, 37(1): 11-23. 
Lawler, P. (1997) ‘Scandinavian Exceptionalism and the European Union’, Journal of Common Market Studies, 35(4): 565-594.

Moene, K. and M. Wallerstein (2006) ‘Social Democracy as a Development Strategy’, in P. Bardhan, S. Bowles and M. Wallerstein (eds) Globalisation and Egalitarian Redistribution, New York: Russel Sage.

Ottesen, L., B. Skirstad, G. Pfister and U. Habermann (2010) 'Gender Relations in Scandinavian Sport Organizations - A Comparison of the Situation and the Policies in Denmark, Norway and Sweden’ Sport in Society, 13(14): 657-675.

Sakslind, R. and O. Skarpenes (2014) 'Morality and Middle Class: The European Pattern and the Norwegian Singularity', Journal of Social History, 48(2): 313-340.

Sanandaji, N. (2015) Scandinavian Unexceptionalism: Culture, Markets and the Failure of Third-Way Socialism, London: Institute of Economic Affairs.

Sanandaji, N. (2016) Debunking Utopia: Exposing the Myth of Nordic Socialism, London: WND.

Trägårdh, L. (2010) 'Rethinking the Nordic Welfare State Through a Neo-Hegelian Theory of State and Civil Society', Journal of Political Ideologies, 15(3): 227-239.

Tvedt, T. (2003) Utviklingshjelp, utenrikspolitikk og makt. Den norske modellen. Oslo: Gyldendal Akademiske.

World Economic Forum (2017) Inclusive Growth and Development Report, Geneva: WEF. 